\title{
In-house setup for laboratory-based x-ray absorption fine structure spectroscopy measurements
}

\author{
F. Zeeshan, J. Hoszowska, (D) L. Loperetti-Tornay, and J.-Cl. Dousse ${ }^{\text {a) }}$ (iD
}

\author{
AFFILIATIONS \\ Physics Department, University of Fribourg, Chemin du Musée 3, CH-1700 Fribourg, Switzerland \\ a) jean-claude.dousse@unifr.ch
}

\begin{abstract}
We report on a laboratory-based facility for in-house x-ray absorption fine structure (XAFS) measurements. The device consists of a conventional $\mathrm{x}$-ray source for the production of the incident polychromatic radiation and a von Hamos bent crystal spectrometer for the analysis of the incoming and transmitted radiation. The reliability of the laboratory-based setup was evaluated by comparing the $\mathrm{Cu} K$-edge and Ta $L_{3}$-edge XAFS spectra obtained in-house with the corresponding spectra measured at a synchrotron radiation facility. To check the accuracy of the device, the $K$ - and $L$-edge energies and the attenuation coefficients below and above the edges of several $3 d, 4 d$, and $5 d$ elements were determined and compared with the existing experimental and theoretical data. The dependence of the XAFS spectrum shape on the oxidation state of the sample was also probed by measuring inhouse the absorption spectra of metallic Fe and two Fe oxides $\left(\mathrm{Fe}_{2} \mathrm{O}_{3}\right.$ and $\left.\mathrm{Fe}_{3} \mathrm{O}_{4}\right)$.
\end{abstract}

Published under license by AIP Publishing. https://doi.org/10.1063/1.5094873

\section{INTRODUCTION}

$\mathrm{X}$-ray absorption fine structure (XAFS) spectroscopy is widely applied at synchrotron radiation (SR) sources where bright, energy tunable, monochromatic, coherent, microfocused, and time-resolved $\mathrm{x}$-ray beams are routinely used to analyze samples in different domains such as physics, ${ }^{1-4}$ chemistry, ${ }^{5,6}$ geology, ${ }^{7}$ biomedicine, ${ }^{8}$ environmental sciences, ${ }^{9}$ cultural heritage, ${ }^{10}$ and archeology. ${ }^{11}$ For external users, however, the access to such advanced research facilities is not easy and the allocated beam time is limited. It can be also noted that many XAFS applications that do not really require fine focus, high flux, or time-resolved $\mathrm{x}$-ray beams are nevertheless performed at SR facilities because of the lack of any alternative.

Alternative methods for XAFS measurements that do not need the full performance of SR beamlines, however, do exist. They are provided by laboratory-based setups that offer the advantages of lower costs and better accessibility. Such setups using conventional $\mathrm{x}$-ray sources have played an important role in the early development of the XAFS technique. ${ }^{12-15}$ Despite the fact that interest in laboratory-based XAFS faded with the advent of thirdgeneration SR sources, the development of laboratory-based XAFS instrumentation continued steadily, ${ }^{16-26}$ with a rapid increase in in-house XAFS applications in the last few years. ${ }^{2}$

The XAFS spectrum of a sample can be measured by means of the transmission, fluorescence, or electron yield method. ${ }^{37,38}$ In the transmission method, the energy of the incident beam is varied step by step and its intensity as well as the intensity of the transmitted beam are measured by ionization chambers or photodiodes. The energy-dependent attenuation coefficient is then deduced from the ratio of the two measured intensities. For transmission measurements, the sample must have an uniform thickness and be free of pinholes. In the fluorescence mode, the incident beam intensity is also measured with an ionization chamber or a photodiode, but instead of measuring the intensity transmitted through the sample, one measures the intensity of the fluorescence $\mathrm{x}$-rays from the sample. The main advantage of the fluorescence method is to permit the study of highly dilute or nonhomogeneous samples that are not suitable for absorption measurements performed in the transmission mode. However, as the fluorescence $\mathrm{x}$-rays can be partly absorbed in the sample, the measured intensity should be corrected for the self-absorption in the case of thick or concentrated samples. In the electron yield method, the electron emission of the sample is measured instead of the fluorescence emission, while the incident 
beam intensity is again determined using an ionization chamber or a photodiode.

As recently demonstrated, an alternative method to measure XAFS spectrum that is insensitive to the self-absorption effect ${ }^{39}$ is the high energy resolution off-resonant spectroscopy (HEROS) technique. ${ }^{40-43}$ The latter combines the irradiation of the sample at a fixed incident beam energy, detuned to below the energy of the absorption edge of interest, with the detection of the sample x-ray fluorescence by means of a curved crystal spectrometer covering an energy range of several tens of electronvolts for fixed positions of the crystal and detector. The main advantage of HEROS is that the XAFS spectra can be measured in a single shot and in very short times, allowing thus the investigation of fast chemical reactions ${ }^{42,44}$ or the use of the XAFS method with $\mathrm{x}$-ray free electron laser (XFEL) beams. $^{41}$

In this work, we present a laboratory-based setup for in-house high energy resolution XAFS measurements in the transmission mode. The bremsstrahlung from a side-window Coolidge-type $\mathrm{x}$ ray tube serves as the incident radiation and a reflection-type von Hamos curved crystal spectrometer is employed as an analyzer. As in the von Hamos geometry, for a given position of the crystal and detector, a certain energy interval is covered by the spectrometer, the XAFS spectra can be collected in a scanless mode of operation. The setup can be used for XAFS measurements around the $K$-edges of elements with $11 \leq Z \leq 38$, $L$-edges of elements with $30 \leq Z \leq 82$, and $M$-edges of elements with $Z \geq 60$.

\section{EXPERIMENTAL SETUP AND METHODOLOGY}

\section{A. von Hamos spectrometer}

The present XAFS equipment is based on the Bragg-type von Hamos curved crystal spectrometer of Fribourg ${ }^{45}$ which was developed primarily for high-resolution XES ( $\mathrm{x}$-ray emission spectroscopy) measurements. In the von Hamos geometry, ${ }^{46}$ the crystal is bent cylindrically, the axis of curvature is parallel to the direction of dispersion, and the crystal curvature provides focusing in the nondispersive plane. In the von Hamos spectrometer of Fribourg

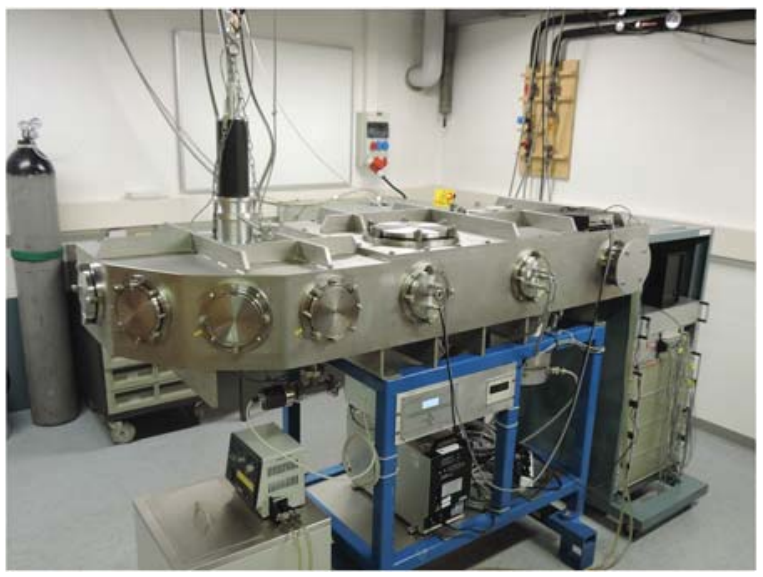

FIG. 1. Photograph of the von Hamos spectrometer of Fribourg as installed for in-house XAFS measurements.
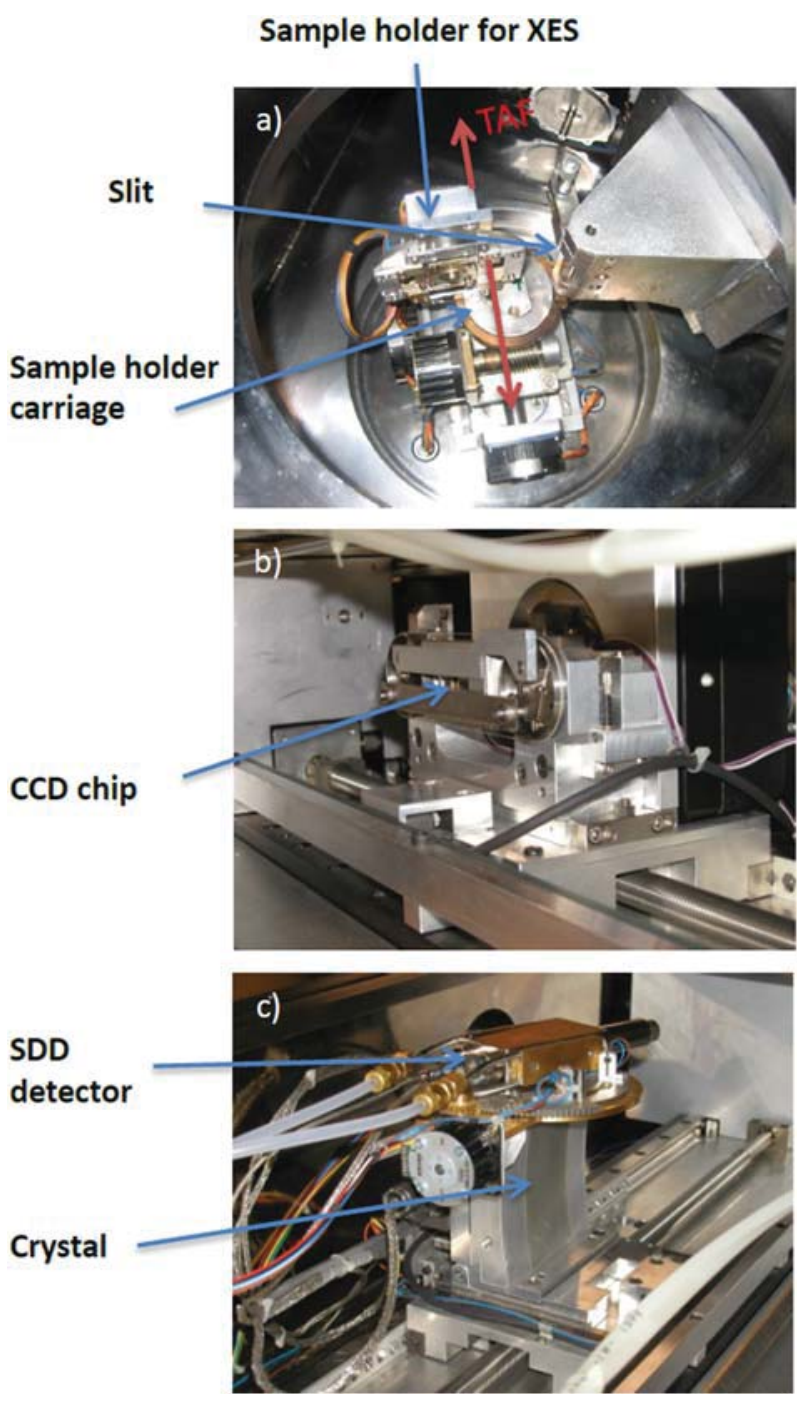

FIG. 2. Photograph of the internal part of the von Hamos vacuum chamber showing (a) the sample holder and slit system (for XES measurements), (b) the CCD detector with the x-ray shutter, and (c) the crystal and silicon drift detector (SDD). The latter mounted on top of the crystal bending block serves to monitor the beam intensity during experiments at external facilities.

(see Figs. 1-3), the dispersion axis is horizontal and the focusing direction vertical, the radius of curvature of the crystal is $25.4 \mathrm{~cm}$, and the diffracted photons are measured with a position-sensitive CCD (charge-coupled device) detector. Depending on the photon energy, a back-illuminated (BI) CCD $(1340 \times 400$ pixels, with a pixel resolution of $20 \mu \mathrm{m}$ and a depletion depth of $15 \mu \mathrm{m})$ or a frontilluminated (FI) deep depleted CCD $(1024 \times 256$ pixels, with a pixel resolution of $27 \mu \mathrm{m}$ and a depletion depth of $50 \mu \mathrm{m}$ ) is used. Both CCD chips were manufactured by the English Electric Valve Company $(\mathrm{EEV})^{47}$ for Roper Scientific ${ }^{48}$ which provides complete CCD systems and related electronics and software. A detailed characterization of the two CCD cameras is given in Ref. 49. Thanks to the 


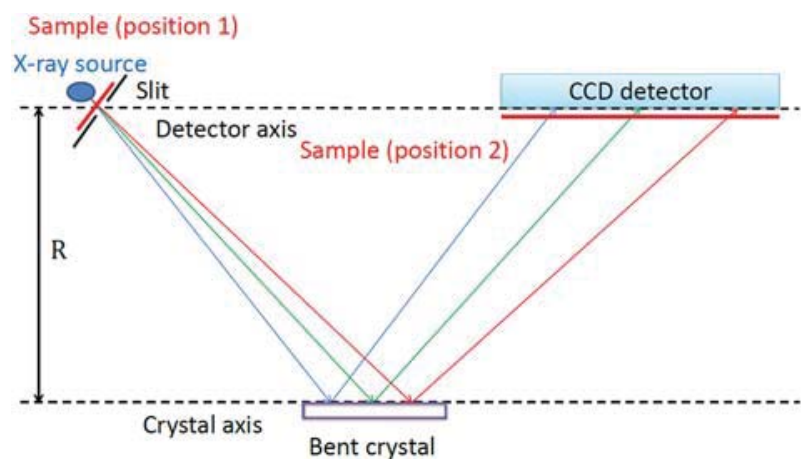

FIG. 3. Schematic drawing (top view) of the von Hamos setup for laboratory-based XAFS measurements. The sample can be placed at either position (1) (in front of the slit) or position (2) (in front of the CCD detector). $\mathrm{R}$ stands for the radius of curvature of the crystal. The x-ray source corresponds to the electron beam spot on the $\mathrm{x}$-ray tube anode.

energy resolution capability of the two CCDs (about $150 \mathrm{eV}$ and $344 \mathrm{eV}$, respectively, at $5.9 \mathrm{keV}$ ), good event pixels are sorted online by setting on the ADC (analog-to-digital converter) of the CCD a charge window corresponding to the energy of the $\mathrm{x}$-rays of interest. A narrow slit placed in front of the sample represents the effective source of radiation.

For a given position of the crystal and detector, photons within a certain energy range can be measured. The latter which depends mainly on the length (in the direction of dispersion) of the CCD varies between some tens to some hundreds of electronvolt. To cover a wider energy range, the crystal and detector are translated along axes that are parallel to the direction of dispersion, the detector twice as much as the crystal. Bragg angles between $24.4^{\circ}$ and $63.2^{\circ}$ can be achieved so that with the use of different crystals an energy range between $0.550 \mathrm{keV}$ and $16.675 \mathrm{keV}$ can be theoretically covered in the first order of diffraction. However, because of the weak efficiency of the CCD detectors below $1 \mathrm{keV}$ and above $15 \mathrm{keV}$, the spectrometer is mostly used for $\mathrm{x}$-ray energies between these two limits.

In XES measurements, since the sample should be located on the straight line joining the crystal center and the slit, upstream from the latter, the sample position must be changed whenever the Bragg angle is modified. This sample alignment is realized by translating the sample along the so-called TAF (target focus) axis (see Fig. 4 in Sec. II C) which is perpendicular to the direction of dispersion. The slit is mechanically coupled to the target carriage through a thin rod so that it remains automatically perpendicular to the direction defined by the sample and crystal centers for any TAF position. During the measurements, the spectrometer chamber is evacuated down to about $10^{-6} \mathrm{hPa}$ with a turbomolecular pump, and the sample, crystal, and detectors are moved, if needed, via remote-controlled stepping motors.

\section{B. XAFS setup}

For XAFS measurements, the spectrometer is operated in the so-called direct geometry. ${ }^{50}$ In this geometry, the sample is replaced by the anode of a side-window $\mathrm{x}$-ray tube that is mounted vertically

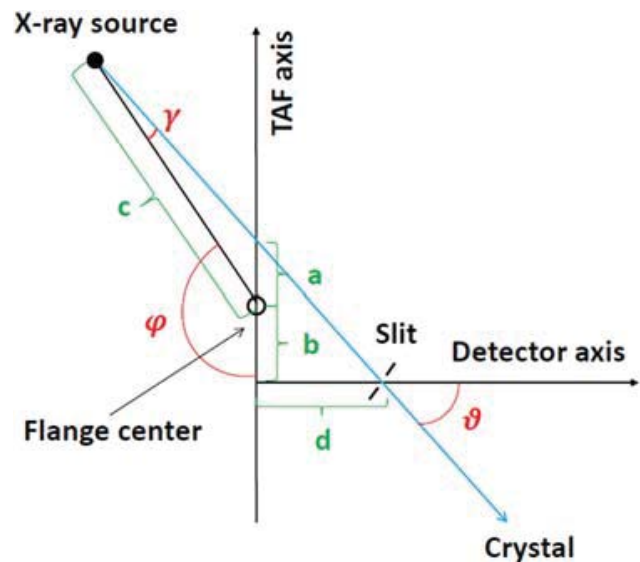

FIG. 4. Schematic drawing showing the lengths $a, b, c$, and $d$, and the angles $\varphi$, $\gamma$, and $\vartheta$ (see text) for the case $\vartheta \geq 41.3^{\circ}$.

on a rotatable flange located above the target chamber of the spectrometer. A vacuum-tight feed through hole in the rotatable flange allows us to insert the $\mathrm{x}$-ray tube nose into the target chamber. The $\mathrm{X}$-ray tube is oriented so that the center of its beryllium window, the center of the slit, and the center of the crystal are all aligned along the direction determined by the Bragg angle corresponding to the centroid energy of the absorption edge to be measured (see Sec. II C). To reduce the scattering of the $\mathrm{x}$-rays in the spectrometer chamber, a copper collimator with a $20 \mathrm{~mm}$ high $\times 5 \mathrm{~mm}$ wide rectangular aperture is mounted on the nose of the $\mathrm{x}$-ray tube in front of the Be window.

XAFS measurements are performed in the transmission mode. The sample can be placed either in front of the slit or in front of the detector (see Fig. 3). When the sample is placed in front of the slit, the Bremsstrahlung from the $\mathrm{x}$-ray tube passes first through the sample and then the transmitted radiation is analyzed by the crystal. When the sample is placed in front of the detector, the Bremsstrahlung is first monochromatized by the crystal and then the fraction of the diffracted radiation that is transmitted through the absorber is detected by the CCD. Note that in both cases, the transmitted intensity $I(E)$ of the Bremsstrahlung x-rays belonging to the energy range selected by the crystal is measured in a straightforward way by the CCD and there is no need to move any element of the spectrometer (scanless measurement).

When the absorber is placed in front of the CCD, the dimensions of the sample should be large enough to cover the CCD surface $\left(2.68 \times 0.80 \mathrm{~cm}^{2}\right.$ and $2.76 \times 0.69 \mathrm{~cm}^{2}$ for the BI and FI CCDs, respectively) and the thickness should be uniform to avoid a fake modulation of the transmitted intensity. In addition, because the Bragg angle $\vartheta$ varies continuously along the dispersion axis of the CCD (see Fig. 3), the thickness $h$ of the absorber can no longer be considered as constant and has to be replaced by $h / \sin (\vartheta)$ in Eq. (5). Experimentally, it is also much easier to insert the absorber in front of the slit, i.e., between the x-ray tube and collimator, than in front of the CCD because the space between the x-ray shutter and front surface of the CCD chip is very narrow [see Fig. 2(b)]. For these reasons, all XAFS measurements presented below were performed with the absorber in front of the slit. 


\section{X-ray tube alignment}

For the XAFS spectra presented in this work, $100 \mathrm{kV} \times 3 \mathrm{~kW}$ Coolidge-type side-window $\mathrm{x}$-ray tubes from Malvern PANanalytical with chromium and copper anodes were used. The thicknesses of the tube windows made of beryllium were $0.5 \mathrm{~mm}$ and $0.3 \mathrm{~mm}$, respectively. The water-cooled $\mathrm{x}$-ray tubes were powered by a current- and voltage-stabilized $\mathrm{x}$-ray generator, allowing to adjust digitally the voltage from 1 to $60 \mathrm{kV}$ by $1 \mathrm{kV}$ steps with an absolute precision of $2 \%$ and a stability of $0.01 \%$ and the current from 1 to $80 \mathrm{~mA}$ by $1 \mathrm{~mA}$ steps with an absolute precision of $1 \%$ and a stability of $0.01 \%$.

The alignment of the $\mathrm{x}$-ray tube that depends on the Bragg angle is realized by rotating the flange supporting the tube by an angle $\varphi$ around a vertical axis passing through the flange center. The accuracy of the flange angular position is about $0.5^{\circ}$, but for a given angle $\varphi$, the reproducibility of the positioning for the measurements $I_{0}$ and $I(E)$ is better $\left(0.02^{\circ}\right)$, thanks to a very simple optical system consisting of a laser pointer mounted on the flange and a reference mark on the laboratory wall behind the spectrometer. As the $\mathrm{x}$-ray tube is not coaxial with the flange, an additional rotation of the tube around its axis by an angle $\gamma$ is required to align the normal to the center of the $\mathrm{x}$-ray tube window on the slit-crystal direction. The angle $y$ is indeed equal to zero only when the straight line joining the crystal and slit centers passes through the center of the flange. According to the schematic drawing presented in Fig. 4, this condition is fulfilled for

$$
\vartheta=\arctan \left[\frac{b}{d}\right] .
$$

As the distances $b$ and $d$ amount to $2.2 \mathrm{~cm}$ and $2.5 \mathrm{~cm}$, respectively, $\vartheta=41.3^{\circ}$. For Bragg angles $\vartheta \neq 41.3^{\circ}, \gamma$ reads as

$$
\gamma=\arcsin \left[\frac{a \cdot \cos (\vartheta)}{c}\right]
$$

where $c=4.5 \mathrm{~cm}$ and the length $a$ is given by

$$
a=d \cdot \tan (\vartheta)-b \text {. }
$$

From the above two equations, one sees that $\gamma>0$ (anticlockwise rotation of the tube) for $\vartheta>41.3^{\circ}$ and $\gamma<0$ (clockwise rotation of the tube) for $\vartheta<41.3^{\circ}$. Finally, as shown in Fig. 4 , the angle $\varphi$ can be written as

$$
\varphi=90^{\circ}+\vartheta+\gamma .
$$

Note that in the standard operation of the von Hamos spectrometer (XES measurements), the x-ray tube is positioned at $\varphi=\gamma=0$.

\section{Methodology}

The measurement of a XAFS spectrum is realized in the following way: first, the crystal and detector are positioned according to the Bragg angle corresponding to the absorption edge of interest. The slit is set perpendicularly to the direction defined by the Bragg angle via the stepping motor of the TAF axis, and the $\mathrm{x}$-ray tube is aligned according to the above-mentioned procedure [see Eqs. (2) and (4)]. The intensity $I_{0}(E)$ of the Bremsstrahlung corresponding to the selected energy region is measured, and then, the measurement is repeated using exactly the same positions for the crystal, detector, and slit, as well as the same orientation, high voltage, and current of the $\mathrm{x}$-ray tube, but this time the sample to be analyzed is inserted in front of the slit or in front of the CCD detector. This second measurement provides the intensity $I(E)$. The attenuation coefficient $\mu(E)$ for the photon energy $E$ is then deduced from the Beer-Lambert law using the following equation:

$$
\mu(E)=\frac{\ln \left(\frac{I_{0}(E)}{I(E)}\right)}{\rho h},
$$

where $\rho$ is the density of the sample and $h$ its thickness.

The thicknesses of the samples were determined from their measured areas $S$ and masses $m$ and their tabulated densities $\rho$ as

$$
h=\frac{m}{\rho A} \text {. }
$$

Note that the sample thickness should be chosen so that the difference between the intensities $I_{0}$ and $I$ of the incident and transmitted beams is large, keeping $I$, however, at a reasonably high enough value. A too thick absorber leads indeed to an attenuation of the $\mathrm{x}$-ray absorption near edge structure (XANES) oscillations and to
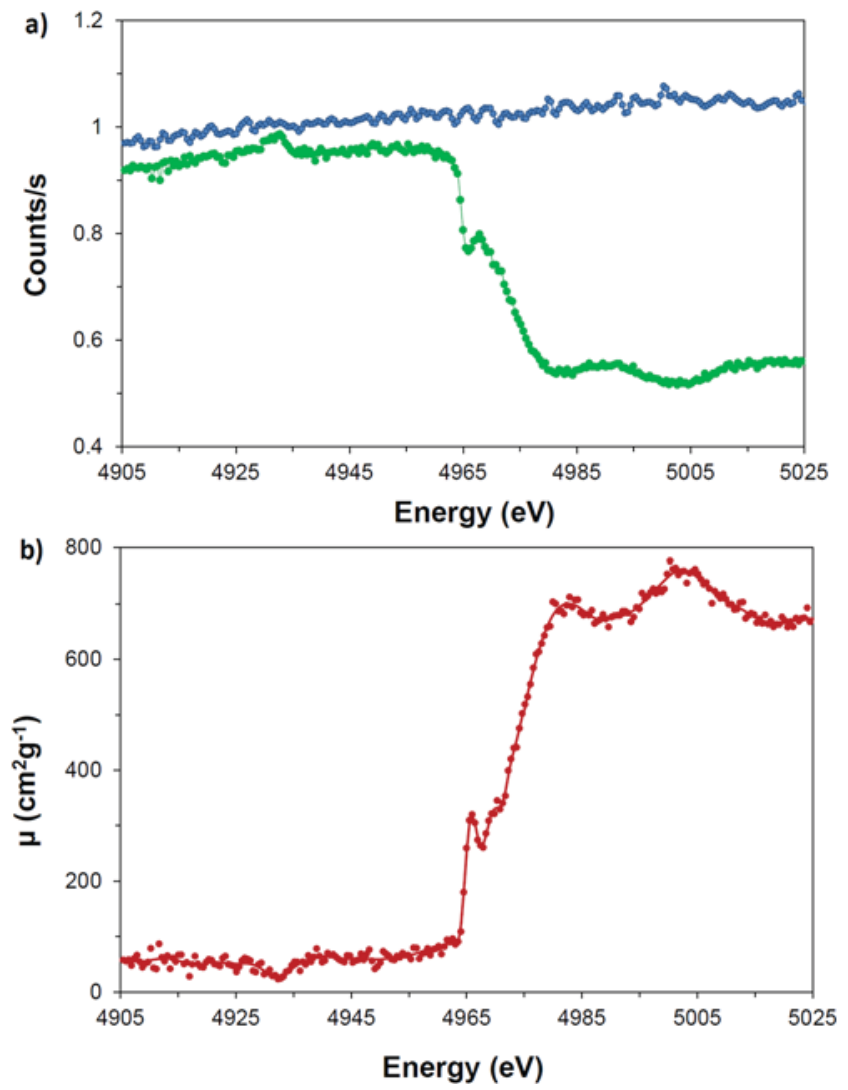

FIG. 5. (a) Measured incident (blue circles) and transmitted (green circles) photon intensities around the $K$-edge of Ti. (b) Attenuation coefficient $\mu(E)$ deduced from (a). The red line is a smoothed curve to guide the eye. The Ti foil thickness was $2.07(5) \mu \mathrm{m}$, and the $\mathrm{Cr}$ anode $\mathrm{x}$-ray tube was operated at $10 \mathrm{kV} \times 10 \mathrm{~mA}$. The measurement was performed using a $\mathrm{Si}(220)$ crystal, and the acquisition times were $8000 \mathrm{~s}$ and $30000 \mathrm{~s}$ for the measurements of $I_{0}$ and $I(E)$, respectively. 
a reduction in the white line intensity, resulting in an apparent shift of the absorption edge energy with the sample thickness. ${ }^{51,52}$ As a rule of thumb, it is generally recommended to choose the absorber thickness $h$ so that $2<\mu \rho h<4$. To preserve the white line shape and intensity, an even smaller sample thickness given by $\mu_{\max } \rho h$ $\leq 1$, where $\mu_{\max }$ represents the maximum value of the attenuation coefficient in the scanned energy region, is suggested in Ref. 53.

For illustration, the intensities $I_{0}(E)$ and $I(E)$ and the resulting attenuation coefficient $\mu(E)$ are depicted for the $K$-edge of Ti in Fig. 5. The first peak observed in the absorption spectrum at $4965 \mathrm{eV}$ corresponds to the white line. The latter is due to the large unoccupancy of $n d$ states in transition metals. ${ }^{54}$ The small peak around $4930 \mathrm{eV}$ in the $I(E)$ spectrum and the corresponding small hole in the absorption spectrum originate from the $K \beta_{1,3} \mathrm{x}$-ray line of $\mathrm{Ti}(4931.81 \mathrm{eV})$. This possibility of having absorption edges and emission lines on the same energy scale represents an interesting feature ${ }^{55}$ of the present system.

\section{COMPARISON WITH SYNCHROTRON RADIATION MEASUREMENTS}

At synchrotron radiation facilities, XAFS measurements are usually performed by scanning the energy of the beam around the absorption edge. In other words, the XAFS spectra are measured step by step, but the intensities $I_{0}(E)$ and $I(E)$ are determined simultaneously and the acquisition time per energy step typically is in the order of 0.1-1 s depending on the experimental method, SR beamline conditions, and sample elemental concentration. As a consequence, a $200 \mathrm{eV}$ wide XAFS spectrum can be measured in less than $15 \mathrm{~min}$, whereas $2-5 \mathrm{~h}$ are needed to measure the same spectrum with a laboratory-based XAFS setup as the one presented in this work. Furthermore, the quick-scanning XAFS acquisition technique and the energy-dispersive approaches allow reaching even subsecond to -minute time resolution for a XAFS spectrum data collection. ${ }^{56}$ Thus, XAFS setups based on conventional $\mathrm{x}$-ray sources cannot compete in terms of measuring times with synchrotron radiation sources, but in most cases, this is not a big disadvantage because the time constraints are not as severe at home as at external big facilities. It should be also noted that in SR-based XAFS measurements, the main interest resides in the determination of the edge energies and XANES oscillations and not in the values of the attenuation coefficients $\mu(E)$, because in the fluorescence and electron yield XAFS techniques that are most commonly used at SR facilities, the coefficients $\mu(E)$ cannot be determined in a straightforward way.

Despite the above-mentioned differences, XAFS spectra obtained from laboratory-based measurements can be compared with those measured at SR facilities to validate the methodology and the setup used in-house. Such comparisons were done in the present work for the $\mathrm{Cu} K$ and Ta $L_{3}$ XAFS spectra. The results are presented in Figs. 6 and 7, respectively.

The SR-based measurement of the $\mathrm{Cu} K$-edge spectrum was performed in the fluorescence mode at the beamline SuperXAS of the Swiss Light Source (SLS). The in-house experiment was performed with a $3-\mu \mathrm{m}$-thick foil, a Cr $\mathrm{x}$-ray tube operated at $15 \mathrm{kV}$ $\times 15 \mathrm{~mA}$, and $\mathrm{a} \mathrm{SiO}_{2}(2 \overline{2} 3)$ crystal. Collecting times of $5000 \mathrm{~s}$ and $30000 \mathrm{~s}$ were used for the measurements of $I_{0}$ and $I(E)$, respectively. The SLS and Fribourg spectra were normalized to overlap

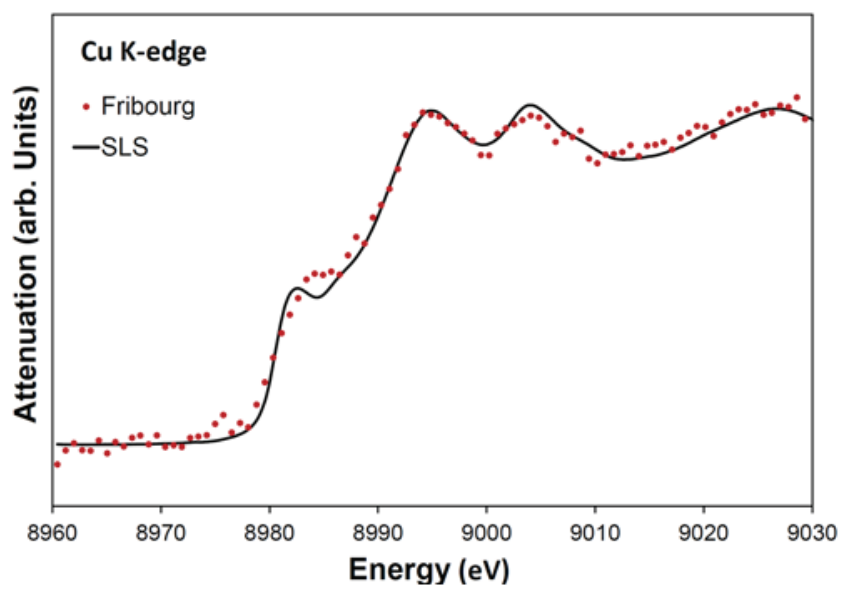

FIG. 6. Shape comparison between the $\mathrm{Cu}$ K-edge absorption spectrum measured at SLS in the fluorescence mode (black solid line) and the corresponding spectrum measured in Fribourg with the laboratory-based setup (red points). The relative uncertainties of the points measured in Fribourg amount to about 10\% (below the edge) and 3\% (above the edge), respectively. The SLS plot was taken from Ref. 41.

as well as possible below and above the edge. As shown, the overall shape of the two spectra is very similar, although the spectrum measured at home is more noisy due to the much weaker photon flux of the conventional x-ray source as compared with the one of the SR beam. On the other hand, the midedge shoulder (at about $8982 \mathrm{eV}$ ) of the spectrum measured in Fribourg is slightly shifted toward higher energy and a little bit broader. The difference in the midedge shoulder width is due to the better energy resolution of the SLS measurement, whereas the energy difference of about $2 \mathrm{eV}$ was assumed to originate from the bigger scatter of the in-house data.

The second comparison concerns the $L_{3}$ XAFS spectrum of a $5-\mu \mathrm{m}$-thick metallic foil of Ta. The SR-based measurement was again performed at the SuperXAS beamline of SLS, but this time

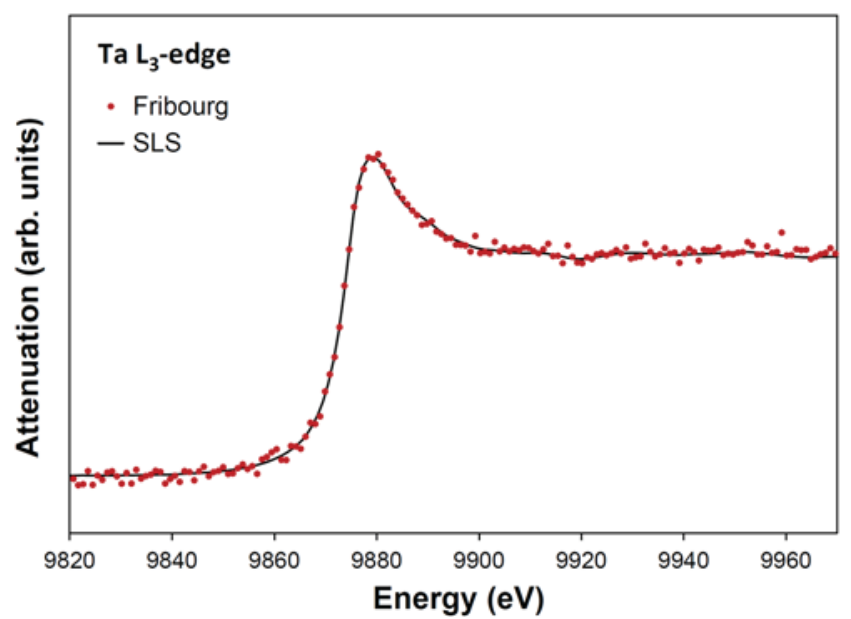

FIG. 7. Same as Fig. 6 but for the Ta $L_{3}$ XAFS spectrum. In this case, the SLS data (taken from Ref. 39) were collected in the transmission mode. 
in the transmission mode. The measurement of Fribourg was performed with a $\mathrm{Ge}(440)$ crystal and a $\mathrm{Cr}$ anode $\mathrm{x}$-ray tube operated at $25 \mathrm{kV} \times 40 \mathrm{~mA}$. Collecting times of $4000 \mathrm{~s}\left(I_{0}\right)$ and $17000 \mathrm{~s} I(E)$ were employed. As can be seen in Fig. 7, the SLS and Fribourg Ta $L_{3}$ XAFS spectra are in excellent agreement, except at about $9956 \mathrm{eV}$ where a small excess of absorption is observed in the spectrum measured at home. The difference, however, is hardly significant within the uncertainty of the experimental data.

\section{EDGE ENERGIES AND ATTENUATION COEFFICIENTS}

To check the reliability and accuracy of the in-house XAFS setup, measurements of the absorption spectra around the $K$-edges of $\mathrm{Ti}, \mathrm{Fe}, \mathrm{Cu}$, and $\mathrm{Ge}$, and around the $L_{3}$-edges of $\mathrm{Mo}, \mathrm{Ag}, \mathrm{Hf}, \mathrm{Ta}$, and $\mathrm{Pt}$ were performed. For Mo and Ag, the XAS spectra around the $L_{2}$ - and $L_{1}$-edges were also measured. All measurements were performed with the same slit width of $0.2 \mathrm{~mm}$ but with different crystals and different high voltages of the x-ray tube. From the measurements, the edge energies and the attenuation coefficients below and above the edges were determined.

For illustration, the $L_{3}$-edge absorption spectrum of $\mathrm{Hf}$ is presented in Fig. 8 and compared with data from the NIST XCOM database. ${ }^{57}$ As the latter do not take into account the processes leading to the XANES and EXAFS structures, plots of the XCOM data over narrow energy ranges correspond to quasistraight lines with slightly negative slopes and a sudden jump of the attenuation coefficient to bigger values at the edge energy.

\section{A. Edge energies}

The location of an absorption edge is not unambiguously defined $^{58}$ and has been variously associated in the literature with (i) the first inflection point of the absorption spectrum, (ii) the energy

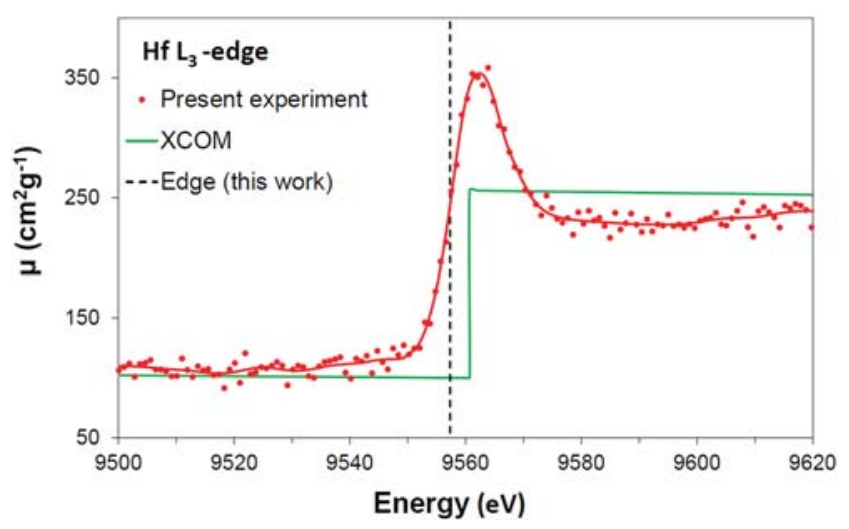

FIG. 8. $L_{3}$-edge XAFS spectrum of $\mathrm{Hf}$. The measurement was performed with a 2.84(7)- $\mu$ m-thick sample, a Si(333) crystal, and a copper anode x-ray tube operated at $15 \mathrm{kV} \times 20 \mathrm{~mA}$. The $I_{0}$ and $I(E)$ spectra were collected in $13000 \mathrm{~s}$ and $30000 \mathrm{~s}$, respectively. The spectrum was calibrated in energy from measurements of the $K \alpha_{1}$ x-ray lines of $\mathrm{Zn}$ and $\mathrm{Ge}$, using the values reported in Ref. 58 for the energies of these transitions. The position of the $L_{3}$-edge is indicated by the vertical dashed line. The green solid line corresponds to the energy-dependent absorption coefficient $\mu(E)$ from the XCOM database (see text). The red solid line (data smoothing) serves only to guide the eye. needed to produce a single core vacancy with the photoelectron "at rest at infinity," and (iii) the energy needed to promote a core electron to the lowest unoccupied state. Note that in the alternative (ii), the absorption edge energies can be determined by combining the electron binding energies of outer shells which can be measured accurately by means of photoelectron spectroscopy with the energies of emission lines involving transition electrons which originate from these outer shells.

The measured XAFS spectra were calibrated in energy by measuring reference $K \mathrm{x}$-ray lines with energies smaller and bigger than the edge energies of interest. The energies of the reference lines were taken from Ref. 58. The method used for the energy calibration of the von Hamos spectrometer is not presented here because it was already described in detail elsewhere (see, e.g., Refs. 45 and 59). In this work, the edge energies were associated with the first inflection points of the absorption spectra. The derivative of the function $\mu(E)$ was computed numerically and then fitted with a Gaussian function. For illustration, the $L_{3}$ absorption spectrum of Mo and the first derivative of the latter are presented in Fig. 9. The maximum value of the derivative which coincides with the inflection point was determined from the energy corresponding to the centroid of the fitted Gaussian function since for symmetric functions the energy corresponding to the maximum value of the function coincides with the centroid of the latter. It was found that the determination of the inflection point was not really sensitive to the choice of the function employed to fit the derivative $d \mu(E) / d E$. Actually, no significant differences could be evinced between the edge energies obtained from the fits of the derivatives performed with Gauss, Lorentz, or Voigt functions. For example, for the $K$-edge of $\mathrm{Cu}$, values of $8980.53 \pm 0.44 \mathrm{eV}, 8980.42 \pm 0.42 \mathrm{eV}$, and $8980.58 \pm 0.39 \mathrm{eV}$ were found by fitting the derivative of the XAFS spectrum with a Gaussian, Lorentzian, and Voigtian function, respectively. As the choice of the fit function was found to be not critical, Gaussian functions were employed for all edges investigated in the present work.

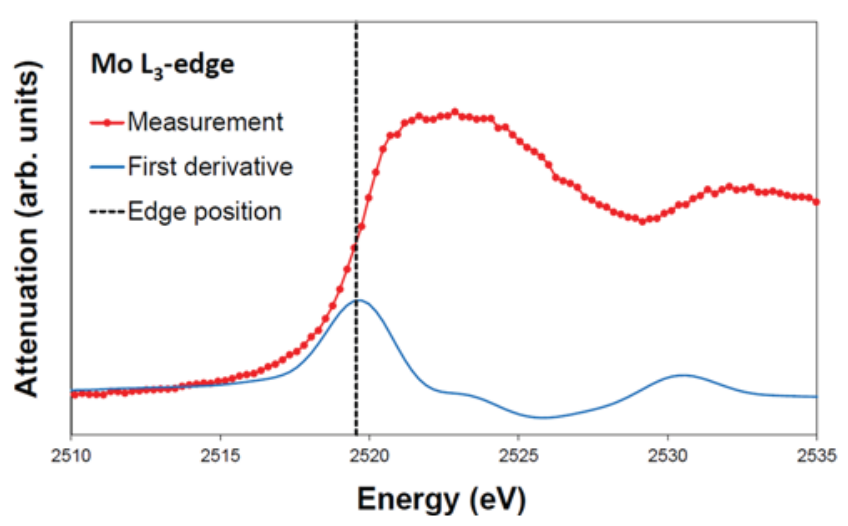

FIG. 9. Mo $L_{3}$-edge spectrum (red circles) and its first derivative (blue line). The edge energy represented by the vertical dashed line was determined from the centroid of the Gaussian used to fit the derivative in the edge region. The measurement was performed with a 1.24(3)- $\mu \mathrm{m}$-thick metallic foil, a Si(111) crystal, and a $\mathrm{Cu}$ anode $\mathrm{x}$-ray tube operated at $4 \mathrm{kV} \times 9 \mathrm{~mA}$. Due to the low value of the employed high voltage, long acquisition times were needed [40000 s for $I_{0}$ and 60000 s for $I(E)]$. 
TABLE I. Comparison between the edge energies determined with the present XAFS setup and other existing experimental values. All energies are given in eV. The notation $4964.65(27 / 9)$ means $4964.65 \pm 0.27$ with an included fit error of 0.09 .

\begin{tabular}{lccccc}
\hline \hline Edge & Present Study & Bearden and Burr ${ }^{60}$ & Bearden $^{61}$ & Other & Kraft $^{4}$ \\
\hline Ti $K$ & $4964.65(27 / 9)$ & $4966.4(6)$ & $4964.58(15)$ & $4964.88(6)^{62}$ & $\ldots$ \\
Fe $K$ & $7111.01(26 / 8)$ & $7112.0(1.3)$ & $7111.28(6)$ & $7110.86(40)^{62}$ & $7110.75(2)$ \\
Cu $K$ & $8980.53(51 / 44)$ & $8978.9(6)$ & $8980.39(48)$ & $8980.5(1.0)^{58}$ & $8980.48(2)$ \\
Ge $K$ & $11103.87(25 / 7)$ & $11103.1(1.0)$ & $11103.76(74)$ & $11103.63(55)^{58}$ & $\ldots$ \\
Mo $L_{1}$ & $2867.59(87 / 83)$ & $2865.5(4)$ & $2880.6(5.0)$ & $2867.20(26)^{58}$ & $\ldots$ \\
Mo $L_{2}$ & $2625.41(26 / 8)$ & $2625.1(4)$ & $2627.3(8)$ & $2625.98(33)^{58}$ & $\ldots$ \\
Mo $L_{3}$ & $2520.44(26 / 7)$ & $2520.2(4)$ & $2523.6(8)$ & $2521.1(1.6)^{58}$ & $\ldots$ \\
Ag $L_{1}$ & $3806.53(50 / 43)$ & $3805.8(4)$ & $3807.3(2)$ & $3807.41(34)^{58}$ & $\ldots$ \\
Ag $L_{2}$ & $3524.98(58 / 52)$ & $3523.7(4)$ & $3525.8(2)$ & $3525.24(26)^{58}$ & $\ldots$ \\
Ag $L_{3}$ & $3352.40(27 / 9)$ & $3351.1(4)$ & $3350.96(13)$ & $3352.58(48)^{58}$ & $\ldots$ \\
Hf $L_{3}$ & $9557.76(40 / 26)$ & $9560.7(6)$ & $9557.7(1.1)$ & $9558.0(1.1)^{58}$ & $9558.29(5)$ \\
Ta $L_{3}$ & $9877.45(35 / 25)$ & $9881.1(4)$ & $9876.7(1.2)$ & $9878.7(2.7)^{58}$ & $\ldots$ \\
Pt $L_{3}$ & $11562.69(48 / 41)$ & $11563.7(4)$ & $11562.3(1.6)$ & $11565.7(3.8)^{58}$ & $11562.76(2)$ \\
\hline
\end{tabular}

The uncertainties on the edge energies quoted in Table I correspond to the uncertainties given by the fits for the Gaussian centroids combined with the uncertainties originating from the energy calibration measurements. The latter include the uncertainties of the reference line energies, the uncertainties originating from the fits of these reference lines, as well as the uncertainties related to the CCD positions. The latter can be determined with a precision of $\pm 1 \mu \mathrm{m}$, thanks to a dedicated optical system.

The edge energies obtained in this work are presented in Table I where they are compared with experimental values reported by Bearden and Burr, ${ }^{60}$ Bearden, ${ }^{61}$ Sevier, ${ }^{62}$ Deslattes et al., ${ }^{58}$ and Kraft et al. ${ }^{4}$ The values reported by Bearden and Burr were obtained from photoelectron spectroscopy measurements, those from Sevier and Deslattes were determined by adding to the energies of $K$ and $L \mathrm{x}$-ray transitions from outer levels the known energies of the latter, while the results obtained by Kraft were derived from synchrotron radiation measurements and the first inflection point method. Regarding the edge energies reported by Bearden, no indication is provided in Ref. 61 about the employed method. The edge energies quoted in the XCOM database $^{57}$ (see, e.g., Fig. 7) are those of Bearden and Burr. ${ }^{60}$

From Table I, one sees that the edge energies reported by Bearden and Burr ${ }^{60}$ are all inconsistent with ours, except for the $L_{2}$ - and $L_{3}$-edges of Mo. The discrepancy cannot be explained by the different definitions of the edge energy used in our work (inflection point of lowest energy) and the one of Bearden and Burr (binding energy of the $1 s$ electron), because some values from Ref. 60 are bigger than ours, some other ones smaller.

The comparison with Bearden's values ${ }^{61}$ is more satisfactory since the latter are in agreement with ours for the $K$-edges and for the $L_{3}$-edges of $\mathrm{Hf}, \mathrm{Ta}$, and $\mathrm{Pt}$, whereas for the $L_{1-3}$-edges of Mo and $\mathrm{Ag}$, discrepancies are observed. Actually, except for the $L_{3}$-edge energy of $\mathrm{Ag}$ which is slightly smaller than ours, the other $L$-edge energies of these two elements are significantly bigger than our values. In the case of the $L_{1}$-edge of Mo, the energy quoted by Bearden overestimates even our result by about $13 \mathrm{eV}$. We guess, however, that some problems were encountered by Bearden in this measurement because the error of $\pm 5 \mathrm{eV}$ reported for this edge is much bigger than the uncertainties quoted for the other edges.

A satisfactory agreement is observed in the comparison of present values with those reported by Sevier ${ }^{62}$ and Deslattes et al. ${ }^{58}$ As mentioned before, the latter were obtained from $\mathrm{x}$-ray transition energies combined with the known binding energies of the outer levels involved in these transitions. Actually, the $K$-edge energies of $\mathrm{Ti}$ and Fe reported by Sevier are very close to our values, while the data from Deslattes are also in good agreement with the results obtained in the present work, except for the $L_{2}$-edge of Mo (deviation of $1.3 \sigma$, where $\sigma$ stands for the combined error of the two results) and $L_{1}$-edge of $\mathrm{Ag}(1.4 \sigma)$. The $L_{3}$-edge energy of Pt reported by Deslattes is $3 \mathrm{eV}$ bigger than our value but nevertheless consistent with it because in this case the error quoted by Deslattes is quite big $(3.8 \mathrm{eV})$.

Finally, the present edge energies are consistent with the data reported by Kraft et al. ${ }^{4}$ for the $K$-edges of $\mathrm{Fe}$ and $\mathrm{Cu}$ and the $L_{3}$ edge of Pt, whereas a deviation of about $1.3 \sigma$ is observed for the $L_{3}$ edge of Hf. The values of Kraft represent probably the most precise and reliable reference data for checking the accuracy of the present values, but unfortunately, $\mathrm{Fe}, \mathrm{Cu}, \mathrm{Hf}$, and $\mathrm{Pt}$ are the single elements common to both experiments.

\section{B. Attenuation coefficients}

The attenuation coefficients $\mu(E)$ were determined from the measured intensities of the incoming $\left(I_{0}\right)$ and transmitted $(I)$ photon beams using Eq. (5). The observed variation of the incoming beam intensity $I_{0}$ with the energy [see Fig. 5(a)] reflects the energy distribution of the Bremsstrahlung emission of the $\mathrm{x}$-ray tube as well as the inhomogeneous intensity of the electron beam spot on the anode of the tube. However, as the experimental setup is exactly the same in the measurements of $I_{0}(E)$ and $I(E)$, the same variations are observed in the spectrum $I(E)$ and the latter do not affect, thus, the determination of the absorption coefficient.

In the XCOM tables, ${ }^{57}$ for each edge energy, two values are given which correspond to the attenuation coefficients just before 
and after the jump, i.e., to $\mu_{b}=\mu\left(E_{<} E_{\text {edge }}\right)$ and $\mu_{a}=\mu\left(E_{>} E_{\text {edge }}\right)$. Thus, for the comparison of the present attenuation coefficients with the data from the XCOM database, ${ }^{57}$ linear functions were fitted to the XAFS data below and above the edges and the values $\mu_{b}$ and $\mu_{a}$ reported in Table II were then obtained by calculating the values of the two linear functions for $E=E_{\text {edge }}$.

Neglecting the uncertainty on the density of the sample, the uncertainty on the absorption coefficient $\mu$ reads as

$$
\Delta \mu=\sqrt{\sigma_{f i t}^{2}+\sigma_{h}^{2}+\sigma_{\text {tube }}^{2}},
$$

where $\sigma_{f i t}$ represents the uncertainty from the linear fitting of the data below and above the edge, $\sigma_{h}$ represents the uncertainty originating from the uncertainty on the sample thickness, and $\sigma_{\text {tube }}$ represents the uncertainty accounting for the intensity variation of the x-ray tube between the $I_{0}(E)$ and $I(E)$ measurements. The uncertainty $\sigma_{h}$ is simply given by

$$
\sigma_{h}=\left|\frac{\partial \mu}{\partial h} \Delta h\right|=\frac{\Delta h}{h} \mu,
$$

whereas $\sigma_{\text {tube }}$ can be expressed as a function of the parameter $\xi$ representing the variation of the x-ray tube intensity between the $I_{0}(E)$ and $I(E)$ measurements,

$$
I(E)=\xi I_{0}(E) e^{-\mu(E) \rho h},
$$

which leads to

$$
\sigma_{\text {tube }}=\frac{1}{\rho h} \frac{\Delta \xi}{\xi}
$$

The relative uncertainty $\Delta \xi / \xi$ was assumed to be $2 \%$.

The attenuation coefficients determined in the present work for photon energies just below and above the edges are presented in Table II, where they are compared with values from the XCOM database ${ }^{57}$ and from the tables of Storm and Israel ${ }^{63}$ and Henke. ${ }^{64}$ In the latter reference, the reported values are only given for energies corresponding to strong $K$ and $L \mathrm{x}$-ray lines of selected elements. For this reason, the coefficients $\mu_{b}\left(E_{\text {edge }}\right)$ and $\mu_{a}\left(E_{\text {edge }}\right)$ listed in Table II were determined from double logarithmic interpolations of the values quoted in Ref. 64 for transition energies below and above the edges of interest. However, as only one or even no value is reported between the $L_{1}$ - and $L_{2}$-edges and between the $L_{2}$ - and $L_{3}$-edges, in the case of the $L$-shell, only the coefficients $\mu_{b}\left(E_{L_{1}-e d g e}\right)$ and $\mu_{a}\left(E_{L_{3}-\text { edge }}\right)$ could be derived.

In the tables of Storm and Israel, it is stated that the relative uncertainties of the attenuation coefficients are in the order of $10 \%$, whereas no indication could be found about the uncertainties affecting the values listed in the $\mathrm{XCOM}^{57}$ and Henke ${ }^{64}$ tables. However, as the values from the three databases are based on similar approaches, the same relative uncertainty of $10 \%$ was assumed for the values quoted in these tables. With this assumption, one can see from the inspection of Table II that all attenuation coefficients determined in the present work are in agreement within the combined uncertainties with the values reported in the three databases, except for the coefficients $\mu_{a}$ of $\mathrm{Fe}$ and $\mathrm{Ge}$ and the coefficient $\mu_{b}$ of the $\mathrm{Ag}$ $L_{3}$-edge which are bigger than the theoretical predictions and differ from the average values of the latter by about $1.4 \sigma, 1.5 \sigma$, and 1.1 $\sigma$, respectively.

Accurate experimental values for the mass attenuation coefficients $\mu(E)$ are scarce in the literature. However, some data from the Laboratoire National Henri Becquerel (LNHB, Paris) were found for the $K$-edges of $\mathrm{Ti}^{65}{ }^{65} \mathrm{Cu},{ }^{66}$ and $\mathrm{Ge},{ }^{67}$ and the $L_{3}$-edges of $\mathrm{Hf}$ and $\mathrm{Pt}^{67}$ These recent experimental XAFS data that were obtained partly at the metrology beamline of the synchrotron radiation facility SOLEIL ${ }^{68}$ and partly with the tunable monochromatic x-ray source SOLEX $^{69}$ are reliable and precise. To obtain the attenuation coefficients $\mu_{b}\left(E_{\text {edge }}\right)$ and $\mu_{a}\left(E_{\text {edge }}\right)$ from the values tabulated in Refs. 65-67, the same method as the one used for our own data was employed, namely linear spline interpolations below and above the edges. For Hf, the strong white line was excluded from the interpolation domain. The obtained values are presented in Table II,

\begin{tabular}{|c|c|c|c|c|c|c|c|c|c|c|}
\hline \multirow[b]{2}{*}{ Edge } & \multicolumn{2}{|c|}{ Present Study } & \multicolumn{2}{|c|}{$\mathrm{XCOM}^{57}$} & \multicolumn{2}{|c|}{ Storm and Israel $^{63}$} & \multicolumn{2}{|c|}{ Henke $^{64}$} & \multicolumn{2}{|c|}{ LNHB } \\
\hline & $\mu_{b}$ & $\mu_{a}$ & $\mu_{b}$ & $\mu_{a}$ & $\mu_{b}$ & $\mu_{a}$ & $\mu_{b}$ & $\mu_{a}$ & $\mu_{b}$ & $\mu_{a}$ \\
\hline $\mathrm{Ti} K$ & $74(11)$ & $716(22)$ & 84 & 684 & 84 & 708 & 83 & 718 & $82.2(2)^{65}$ & $737.2(1.1)^{65}$ \\
\hline $\mathrm{Fe} K$ & $55(7)$ & $352(11)$ & 53 & 408 & 53 & 414 & 51 & 412 & $\ldots$ & $\ldots$ \\
\hline $\mathrm{Cu} K$ & $40(4)$ & $309(9)$ & 38 & 278 & 38 & 285 & 37 & 289 & $37.5(1)^{66}$ & $305.6(1.3)^{66}$ \\
\hline Ge $K$ & $30(12)$ & $237(12)$ & 28 & 198 & 28 & 202 & 27 & 208 & $27.8(2)^{67}$ & $207.6(7)^{67}$ \\
\hline Mo $L_{1}$ & $1943(48)$ & $2259(56)$ & 1961 & 2243 & 1952 & 2235 & $\ldots$ & 2245 & $\ldots$ & $\ldots$ \\
\hline Mo $L_{2}$ & $1652(41)$ & $2518(71)$ & 1750 & 2433 & 1758 & 2410 & $\ldots$ & $\ldots$ & $\ldots$ & $\ldots$ \\
\hline $\operatorname{Mo~} L_{3}$ & $597(17)$ & $1924(53)$ & 542 & 1979 & 539 & 1940 & 542 & $\ldots$ & $\ldots$ & $\ldots$ \\
\hline $\operatorname{Ag} L_{1}$ & $1317(35)$ & $1471(39)$ & 1282 & 1468 & 1267 & 1457 & $\ldots$ & 1465 & $\ldots$ & $\ldots$ \\
\hline $\operatorname{Ag} L_{2}$ & $1132(30)$ & $1507(40)$ & 1126 & 1547 & 1122 & 1535 & $\ldots$ & $\ldots$ & $\ldots$ & $\ldots$ \\
\hline $\operatorname{Ag} L_{3}$ & $432(14)$ & $1205(33)$ & 389 & 1274 & 386 & 1267 & 385 & $\ldots$ & $\ldots$ & $\ldots$ \\
\hline $\mathrm{Hf} L_{3}$ & $101(4)$ & $252(7)$ & 100 & 256 & 99 & 262 & 102 & $\ldots$ & $97.8(2)^{67}$ & $248.4(5)^{67}$ \\
\hline $\mathrm{Ta} L_{3}$ & $104(4)$ & $230(7)$ & 96 & 244 & 95 & 250 & 93 & $\ldots$ & $\ldots$ & $\ldots$ \\
\hline Pt $L_{3}$ & $78(3)$ & $196(6)$ & 78 & 195 & 77 & 197 & 76 & $\ldots$ & $75.1(1)^{67}$ & $186.2(3)^{67}$ \\
\hline
\end{tabular}

TABLE II. Comparison between the attenuation coefficients $\mu_{b}$ (below the edge) and $\mu_{a}$ (above the edge) obtained with the present XAFS setup and values from the existing databases. For the $\mathrm{K}$-edges of $\mathrm{Cu}$ and $\mathrm{Ge}$ and the $L_{3}$-edges of $\mathrm{Hf}$ and $\mathrm{Pt}$, the comparison was extended to the recent and precise experimental values determined at the "Laboratoire National Henri Becquerel" (LNHB). All values are given in $\mathrm{cm}^{2} / \mathrm{g}$. 
where they are compared with the present results. As can be seen, a quite satisfactory agreement is observed, except for the coefficients $\mu_{a}$ of the $K$-edge of $\mathrm{Ge}$ and the $L_{3}$-edge of $\mathrm{Pt}$ for which our values are bigger than those of LNHB by about $2.4 \sigma$ and $1.6 \sigma$, respectively.

\section{COMPARISON BETWEEN $K$-EDGE XAFS SPECTRA OF METALLIC IRON AND IRON OXIDES}

Samples of metallic $\mathrm{Fe}\left(\mathrm{Fe}^{0}\right)$ and $\mathrm{Fe}_{2} \mathrm{O}_{3}\left(\mathrm{Fe}^{3+}\right)$ and $\mathrm{Fe}_{3} \mathrm{O}_{4}$ $\left(\mathrm{Fe}^{2+, 3+}\right)$ oxides were measured. To probe the sensitivity of the XAFS spectra to the size of the particles in the case of powder samples, two $\mathrm{Fe}_{2} \mathrm{O}_{3}$ powders were measured: the first one with a particle size of $\leq 5 \mu \mathrm{m}$ and the second one with a particle size of 5-25 $\mathrm{nm}$. The grain size of the $\mathrm{Fe}_{3} \mathrm{O}_{4}$ powder was also $\leq 5 \mu \mathrm{m}$. The sample thicknesses were $1.62 \mathrm{mg} / \mathrm{cm}^{2}, 2.80 \mathrm{mg} / \mathrm{cm}^{2}, 1.80 \mathrm{mg} / \mathrm{cm}^{2}$, and $2.95 \mathrm{mg} / \mathrm{cm}^{2}$ for the metallic $\mathrm{Fe}$ foil, $\mathrm{Fe}_{2} \mathrm{O}_{3}, \mathrm{Fe}_{3} \mathrm{O}_{4}$ powders, and $\mathrm{Fe}_{2} \mathrm{O}_{3}$ nanopowder, respectively. The measurements were performed with a $\mathrm{Cu} \mathrm{x}$-ray tube operated at $40 \mathrm{kV} \times 30 \mathrm{~mA}$ and a $\mathrm{SiO}_{2}(2 \overline{2} 3)$ crystal. The acquisition time was $10000 \mathrm{~s}$ for each spectrum. Because residuals of the $K \alpha_{1,2}$ characteristic $\mathrm{x}$-ray lines of $\mathrm{Cu}$ from the tube were observed in the spectrum during test measurements, a $20-\mu \mathrm{m}$-thick foil of Co was installed in front of the collimator as a filter, resulting in an attenuation by a factor 2.8 of the good signal and by a factor of about 300 of the parasitic $K \alpha_{1,2}$ lines of $\mathrm{Cu}$. The energy calibration of the spectra was performed by measuring the $K \alpha_{1}$ lines of Co and $\mathrm{Ni}$, using the transition energies reported in Ref. 58 as references.

The four XAFS spectra are depicted in Fig. 10. As can be seen, obvious differences are observed in the XANES oscillations between Fe metal and $\mathrm{Fe}$ oxides as well as between the micropowder and nanopowder samples of $\mathrm{Fe}_{2} \mathrm{O}_{3}$. For each absorber, the edge energy was determined with the first inflection point method. Values of

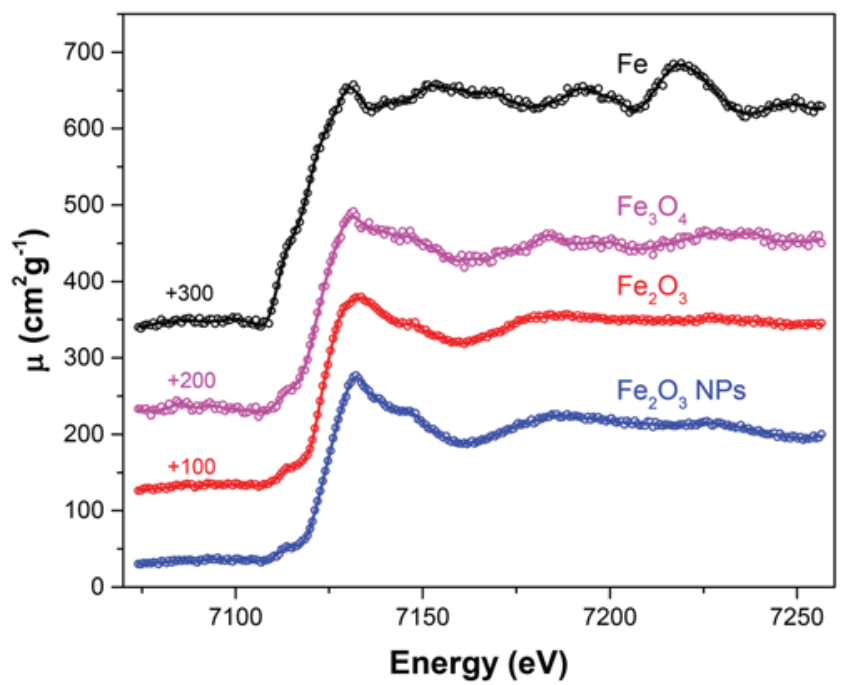

FIG. 10. Comparison between the $\mathrm{K}$-edge XAFS spectra of metallic $\mathrm{Fe}, \mathrm{Fe}_{2} \mathrm{O}_{3}$ and $\mathrm{Fe}_{3} \mathrm{O}_{4}$ oxides. For $\mathrm{Fe}_{2} \mathrm{O}_{3}$, two samples with grain sizes of $\leq 5 \mu \mathrm{m}$ and 5-25 $\mathrm{nm}$ (NPs) were measured. For clarity, offsets in the vertical scale of $+100,+200$, and $+300 \mathrm{~cm}^{2} / \mathrm{g}$ were used for the XAFS spectra of $\mathrm{Fe}_{2} \mathrm{O}_{3}, \mathrm{Fe}_{3} \mathrm{O}_{4}$, and Fe metal, respectively.
7110.82(2) eV, 7111.78(6) eV, 7111.89(9) eV, and 7111.97(6) eV were found for $\mathrm{Fe}, \mathrm{Fe}_{3} \mathrm{O}_{4}, \mathrm{Fe}_{2} \mathrm{O}_{3}$, and $\mathrm{Fe}_{2} \mathrm{O}_{3} \mathrm{NPs}$, respectively. Note that for metallic $\mathrm{Fe}$, the edge energy is consistent within the combined uncertainties, with the value of $7111.01(26) \mathrm{eV}$ (see Table I) found in another measurement performed with the $\mathrm{Cr} \mathrm{x}$-ray tube and very close to the value of $7110.75 \mathrm{eV}$ obtained by $\mathrm{Kraft}^{4}$ with SR. Regarding the difference of $0.08 \mathrm{eV}$ between the edge energies of the $\mathrm{Fe}_{2} \mathrm{O}_{3}$ micro- and nanopowder samples, no definitive conclusion can be drawn because this difference is smaller than the combined uncertainty of $0.11 \mathrm{eV}$. Furthermore, assuming that the energy shift of the oxide edges varies linearly with the degree of oxidation, one finds that the average oxidation state of $\mathrm{Fe}_{3} \mathrm{O}_{4}$ should be 2.69(17), in good agreement with the expected value of 2.67 corresponding to the known valence ratio of $1 / 2$, i.e., $1 / 3 \mathrm{Fe}^{2+}$ and $2 / 3 \mathrm{Fe}^{3+}$, of the $\mathrm{Fe}_{2} \mathrm{O}_{3}$ oxide.

\section{SUMMARY AND CONCLUDING REMARKS}

A laboratory-based setup for in-house XAFS measurements was developed and commissioned. The setup is based on the von Hamos bent crystal spectrometer of Fribourg, and the source of radiation is an $\mathrm{X}$-ray tube. The new setup was validated by measuring the XAS spectra around the $K$-edges and $L$-edges of several solid samples. The shapes of the $K$-edge of $\mathrm{Cu}$ and $L_{3}$-edge of Ta were compared with those measured with synchrotron radiation at the SLS. The spectra were found to overlap very well in both cases. The sensitivity to chemical effects of the XAFS spectra measured with the in-house setup was demonstrated for metallic $\mathrm{Fe}$ and Fe oxides. Furthermore, the edge energies and attenuation coefficients below and above the $K$-edges of $\mathrm{Ti}, \mathrm{Fe}, \mathrm{Cu}$, and $\mathrm{Ge}, L_{1-3}$-edges of $\mathrm{Mo}$ and $\mathrm{Ag}$, and $L_{3}$-edges of $\mathrm{Hf}, \mathrm{Ta}$, and $\mathrm{Pt}$ were extracted from the measurements and compared with the data from the existing theoretical and experimental databases.

The present edge energies were determined from the inflection points of lowest energy. The so-determined edge energies were found to be in good agreement with the recent and reliable values obtained with synchrotron radiation ${ }^{4}$ and with values derived from $\mathrm{x}$-ray transition energies combined with the energies of the outer levels involved in these transitions. ${ }^{58}$ In contrast to that, most of the edge energies reported by Bearden ${ }^{61}$ and to a smaller extent by Bearden and Burr ${ }^{60}$ were found to be inconsistent with our values.

The attenuation coefficients just below and just above the edges were determined by calculating the values at the edge energies of the linear functions obtained from spline interpolations of the XAFS data points measured below and above the edges. The results were compared with values from three different databases, namely the NIST XCOM,,${ }^{57}$ Storm and Israel, ${ }^{63}$ and Henke ${ }^{64}$ databases, and to the recent experimental data from the LNHB. ${ }^{65-67}$ In both cases, a quite good agreement was observed, except for $\mathrm{Ge}$ and $\mathrm{Pt}$ for which the present attenuation coefficients above the edge were found to slightly overestimate the literature values.

A clear advantage of the in-house setup presented in this work is its simplicity and better availability as compared with the SRbased equipment. In counterpart, the data taken with the laboratorybased setup are more noisy due to the significantly lower intensity of the employed $\mathrm{x}$-ray source. For the same reason, the data collection times are longer than at SR facilities by about one order of magnitude for standard XAFS measurements. Actually, to avoid a 
contamination of the XAFS spectra by higher energy photons, most of the present measurements were performed at low values of the $\mathrm{x}$-ray tube voltage and current, i.e., with detected photon intensities $I_{0}(E)$ in the order of several photons/s. However, thanks to the energy resolution capability of the CCD, higher energy photons can be suppressed very efficiently by applying narrow energy windows to the CCD so that probably most of the measurements could have been performed at higher x-ray tube voltages (e.g., $60 \mathrm{kV}$ ) and currents and thus with about 10-20 times higher incoming photon intensities. It should be noted, however, that the CCD detector is count rate limited to about 20 photons/s over the 400 (BI CCD) or 256 (FI CCD) pixels in the nondispersive direction in order to avoid multiple hit events. As depicted in Fig. 5 for the $K$-edge of Ti measured at $10 \mathrm{kV}$ and $10 \mathrm{~mA}, I_{0}(E)$ is about 1 photon/s. The $40 \mathrm{kV}$ $\times 30 \mathrm{~mA} \mathrm{x}$-ray tube operating conditions for the Fe XAFS spectra (Fig. 10) yield $I_{0}(E)$ count rates of 5.5 photons/s. In the case of the Ta XAFS shown in Fig. 7, for $I_{0}(E)$, count rates of 20 photons/s at an operating voltage of $25 \mathrm{kV}$ and current of $40 \mathrm{~mA}$ for a Cr x-ray tube were achieved. The present $I_{0}(E)$ count rate of 20 photons/s is thus comparable with the one of about 30 photons/s reported in Ref. 30 for the $\mathrm{NiO} K$-edge measurement at $10 \mathrm{kV} \times 40 \mathrm{~mA}$.

A further weak point of the in-house setup resides in the fact that the spectra $I_{0}(E)$ and $I(E)$ are not measured simultaneously but sequentially. This drawback could be eliminated, however, by monitoring the $\mathrm{x}$-ray tube intensity with a SDD detector placed above the crystal, but then the sample should be placed in front of the CCD and not in front of the slit. An elegant alternative solution would consist to place again the sample in front of the CCD but to cover only the top half part of the latter (i.e., rows 201-400 for the BI CCD) with the sample and to leave the bottom part (rows 1-200) uncovered. By projecting then separately the top and bottom CCD rows onto the dispersion axis, simultaneous $I(E)$ and $I_{0}(E)$ spectra would be obtained. In the latter two cases, however, the sample should be at least as long as the CCD, be free of pinholes, and have a highly homogeneous thickness.

In conclusion, it has been proven that XAFS measurements are feasible by means of the presented in-house setup and that the obtained results (XAFS spectrum shapes, edge energies, and attenuation coefficients) are reliable. Although laboratory-based XAFS setups cannot compete with the SR-based ones in terms of photon beam intensities and the duration of the measurements, the two techniques can be considered as complementary and both useful for academic research and industrial applications.

\section{ACKNOWLEDGMENTS}

The financial support of the Swiss National Science Foundation is acknowledged (Grant No. 200020-146739).

\section{REFERENCES}

${ }^{1}$ L. A. Grunes, Phys. Rev. B 27, 2111 (1983).

${ }^{2}$ K. W. Nam, W. S. Yoon, and K. B. Kim, Electrochim. Acta 47, 3201 (2002).

${ }^{3}$ T. Matsushita and R. P. Phizackerley, Jpn. J. Appl. Phys., Part 1 20, 2223 (1981).

${ }^{4}$ S. Kraft, J. Stümpel, P. Becker, and U. Kuetgens, Rev. Sci. Instrum. 67, 681 (1996).

${ }^{\mathbf{5}}$ T. J. Regan, C. Stamm, F. Nolting, J. Lüning, J. Stöhr, and R. L. White, Phys. Rev.

B 64, 214422 (2001).

${ }^{6}$ I. J. Pickering, R. C. Prince, T. Divers, and G. N. George, FEBS Lett. 441, 11 (1998).
${ }^{7}$ M. E. Fleet, C. T. Herzberg, G. S. Henderson, E. D. Crozier, M. D. Osborne, and C. M. Scarfe, Geochim. Cosmochim. Acta 48, 1455 (1984).

${ }^{8}$ L. M. Miller, Q. Wang, T. P. Pelivala, R. J. Smith, A. Lanzirotti, and J. Miklossy, J. Struct. Biol. 155, 30 (2006).

${ }^{9}$ D. E. Salt, R. C. Prince, A. J. M. Baker, I. Raskin, and I. J. Pickering, Environ. Sci. Technol. 33, 713 (1999).

${ }^{10}$ M. G. Dowsett and A. Adriaens, Anal. Chem. 78, 3360 (2006).

${ }^{11}$ S. Reguer, P. Dillmann, F. Mirambet, J. Susini, and P. Lagarde, Appl. Phys. A 83, 189 (2006).

${ }^{12}$ D. E. Sayers, E. A. Stern, and F. W. Lytle, Phys. Rev. Lett. 27, 1204 (1971).

${ }^{13}$ F. W. Lytle, D. E. Sayers, and E. A. Stern, Phys. Rev. B 11, 4825 (1975).

${ }^{14}$ E. A. Stern, D. E. Sayers, and P. W. Lytle, Phys. Rev. B 11, 4836 (1975).

${ }^{15}$ E. A. Stern, Laboratory EXAFS Facilities (American Institute of Physics, New York, 1980).

${ }^{16}$ K. Nishihagi, A. Kawabata, and K. Taniguchi, Jpn. J. Appl. Phys., Part 1 32, 258 (1993).

${ }^{17}$ Y. Inada, S. Funahashi, and H. Ohtaki, Rev. Sci. Instrum. 65, 18 (1994).

${ }^{18}$ P. Lecante, J. Jaud, A. Mosset, J. Galy, and A. Burian, Rev. Sci. Instrum. 65, 845 (1994).

${ }^{19}$ J. Hoszowska and J.-Cl. Dousse, J. Phys. B: At., Mol. Opt. Phys. 29, 1641 (1996).

${ }^{20}$ Y. Inada and S. Funahashi, Z. Naturforsch. 52, 711 (1997).

${ }^{21}$ K. Sakurai and X. M. Guo, Spectrochim. Acta, Part B 54, 99 (1999).

${ }^{22}$ T. Taguchi, Q. F. Xiao, and J. Harada, J. Synchrotron Radiat. 6, 170 (1999).

${ }^{23}$ T. Taguchi, J. Harada, A. Kiku, K. Tohji, and K. Shinoda, J. Synchrotron Radiat. 8, 363 (2001).

${ }^{24}$ T. Taguchi, K. Shinoda, and K. Tohji, Phys. Scr. T115, 1017 (2005).

${ }^{25}$ Y. N. Yuryev, H.-J. Lee, H.-M. Park, Y.-K. Cho, and M.-K. Lee, Rev. Sci. Instrum. 78, 025108 (2007).

${ }^{26}$ M. Szlachetko, M. Berset, J.-Cl. Dousse, J. Hoszowska, and J. Szlachetko, Rev. Sci. Instrum. 84, 093104 (2013).

${ }^{27}$ G. T. Seidler, D. R. Mortensen, A. J. Remesnik, J. I. Pacold, N. A. Ball, N. Barry, M. Styczinski, and O. R. Hoidn, Rev. Sci. Instrum. 85, 113906 (2014).

${ }^{28}$ C. Schlesiger, L. Anklamm, H. Stiel, W. Malzer, and B. Kanngiesser, J. Anal. At. Spectrom. 30, 1080 (2015).

${ }^{29}$ I. Mantouvalou, K. Witte, W. Martyanov, A. Jonas, D. Grötzsch, C. Streeck, H. Löchel, I. Rudolph, A. Erko, H. Stiel, and B. Kanngießer, Appl. Phys. Lett. 108, 201106 (2016).

${ }^{30}$ Z. Németh, J. Szlachetko, E. G. Bajnóczi, and G. Vankó, Rev. Sci. Instrum. 87, 103105 (2016).

${ }^{31}$ J. G. Moya-Cancino, A.-P. Honkanen, A. M. J. van der Herden, H. Schaink, L. Folkertsma, M. Ghiasi, A. Longo, F. M. F. de Groot, F. Meirer, S. Huotari, and B. M. Weckhuysen, Chem CatChem 11, 1039 (2019).

${ }^{32}$ E. P. Jahrman, W. M. Holden, A. S. Ditter, D. R. Mortensen, G. T. Seidler, T. T. Fister, S. A. Kosimor, L. F. J. Piper, J. Rana, N. C. Hyatt, and M. C. Stennett, Rev. Sci. Instrum. 90, 024106 (2019).

${ }^{33}$ G. T. Seidler, D. R. Mortensen, A. S. Ditter, N. A. Ball, and A. J. Remesnik, J. Phys.: Conf. Ser. 712, 012015 (2016).

${ }^{34}$ R. Bès, T. Ahopelto, A.-P. Honkanen, S. Huotari, G. Leinders, J. Pakarinen, and K. Kvashina, J. Nucl. Mater. 507, 50 (2018).

${ }^{35}$ A.-P. Honkanen, S. Hollikkala, T. Ahopelto, A.-J. Kallio, M. Blomberg, and S. Huotari, Rev. Sci. Instrum. 90, 035002 (2019).

${ }^{36}$ W. Blachucki, J. Czapla-Masztafiak, J. Sá, and J. Szlachetko, J. Anal. At. Spectrom. 34, 1409 (2019).

${ }^{37}$ J. Jaklevic, J. A. Kirby, M. P. Klein, A. S. Robertson, G. S. Brown, and P. Eisenberger, Solid State Commun. 23, 679 (1977).

${ }^{38}$ W. Gudat and C. Kunz, Phys. Rev. Lett. 29, 169 (1972).

${ }^{39}$ W. Blachucki, J. Szalchetko, J. Hoszowska, J.-Cl. Dousse, Y. Kayser, M. Nachtegaal, and J. Sá, Phys. Rev. Lett. 112, 173003 (2014).

${ }^{40}$ J. Szlachetko, M. Nachtegaal, J. Sá, J.-Cl. Dousse, J. Hoszowska, E. Kleymenov, M. Janousch, O. V. Safonova, C. König, and J. A. van Bokhoven, Chem. Commun. 48, 10898 (2012). 
${ }^{41}$ J. Szlachetko, C. J. Milne, J. Hoszowska, J.-Cl. Dousse, W. Blachucki, J. Sá, Y. Kayser, M. Messerschmidt, R. Abela, S. Boutet, C. David, G. Williams, M. Pajek, B. D. Patterson, G. Smolentsev, J. A. van Bokhoven, and M. Nachtegaal, Struct. Dyn. 1, 021101 (2014).

${ }^{42}$ J. Szlachetko, J. Sá, M. Nachtegaal, U. Hartfelder, J.-Cl. Dousse, J. Hoszowska, D. L. Abreu Fernandes, H. Shi, and C. Stampfl, J. Phys. Chem. Lett. 5, 80 (2014).

${ }^{43}$ W. Blachucki, J. Hoszowska, J.-Cl. Dousse, Y. Kayser, R. Stachura, K. Tyrala, K. Wojtaszek, J. Sá, and J. Szlachetko, Spectrochim. Acta, Part B 136, 23 (2017).

${ }^{44}$ W. Blachucki, J. Szlachetko, Y. Kayser, J.-Cl. Dousse, J. Hoszowska, F. Zeeshan, and J. Sá, Nucl. Instrum. Methods Phys. Res., Sect. B 411, 63 (2017).

${ }^{45}$ J. Hoszowska, J.-Cl. Dousse, J. Kern, and C. Rhême, Nucl. Instrum. Methods Phys. Res., Sect. A 376, 129 (1996).

${ }^{46}$ L. von Hamos, Ann. Phys. 409, 716 (1933).

${ }^{47}$ See https://www.teledyne-e2v.com/ for details about English Electric Valve Company (now Teledyne e2v).

${ }^{48}$ See www.roperscientific.com for details about this Roper Scientific.

${ }^{49}$ J. Szlachetko, J.-Cl. Dousse, J. Hoszowska, M. Berset, W. Cao, M. Szlachetko, and M. Kavčič, Rev. Sci. Instrum. 78, 093102 (2007).

${ }^{50}$ F. Zeeshan, J.-Cl. Dousse, and J. Hoszowska, J. Electron Spectrosc. Relat. Phenom. 233, 11 (2019).

${ }^{51}$ L. G. Parratt, C. F. Hempstead, and E. L. Jossem, Phys. Rev. 105, 1228 (1957).

${ }^{52}$ M. Bianchini and P. Glatzel, J. Synchrotron Radiat. 19, 911 (2012).

${ }^{53}$ E. A. Stern and K. Kim, Phys. Rev. B 23, 3781 (1981).

${ }^{54}$ J. E. Müller, O. Jepsen, and J. W. Wilkins, Solid State Commun. 42, 365 (1982).
${ }^{55}$ R. A. Valenza, E. P. Jahrman, J. J. Kas, and G. T. Seidler, Phys. Rev. B 96, 032504 (2017).

${ }^{56}$ A. A. Guda, A. L. Bugaev, R. Kopelent, L. Braglia, A. V. Soldatov, M. Nachtegaal, O. V. Safonova, and G. Smolentsev, J. Synchrotron Radiat. 25, 989 (2018).

${ }^{57}$ See http://www.nist.gov/pml/data/xcom/ for the NIST Database search form.

${ }^{58}$ R. D. Deslattes, E. G. Kessler, P. Indelicato, L. de Billy, E. Lindroth, and L. Anton, Rev. Mod. Phys. 75, 35 (2003).

${ }^{59}$ Y.-P. Maillard, J.-Cl. Dousse, J. Hoszowska, M. Berset, O. Mauron, P.A. Raboud, M. Kavčič, J. Rzadkiewicz, D. Banaś, and K. Tökési, Phys. Rev. A 98, 012705 (2018).

${ }^{60}$ J. A. Bearden and A. F. Burr, Rev. Mod. Phys. 39, 125 (1967).

${ }^{61}$ J. A. Bearden, Rev. Mod. Phys. 39, 78 (1967).

${ }^{62}$ K. D. Sevier, At. Data Nucl. Data Tables 24, 323 (1979).

${ }^{63}$ E. Storm and H. I. Israel, Nucl. Data Tables 7, 565 (1970).

${ }^{64}$ B. L. Henke, E. M. Gullikson, and J. C. Davis, At. Data Nucl. Data Tables 54, 181 (1993).

${ }^{65}$ Y. Ménesguen, C. Dulieu, and M.-C. Lépy, "Advances in the measurements of the mass attenuation coefficients," X-Ray Spectrom. (published online 2018).

${ }^{66}$ Y. Ménesguen and M.-C. Lépy, Metrologia 53, 7 (2016).

${ }^{67}$ Y. Ménesguen, private communication (2017).

${ }^{68}$ Y. Ménesguen and M.-C. Lépy, X-Ray Spectrom. 40, 411 (2011).

${ }^{69}$ C. Bonnelle, P. Jonnard, J.-M. André, A. Avila, D. Laporte, H. Ringuenet, M.C. Lépy, J. Plagnard, L. Ferreux, and J. C. Protas, Nucl. Instrum. Methods Phys. Res., Sect. A 516, 594 (2004). 